\title{
O USO DE HQ PARA O ENSINO DE CONCEITOS HISTÓRICOS DE SEGUNDA ORDEM
}

\section{THE USAGE OF COMICS IN TEACHING HISTORICAL CONCEPTS}

\author{
Brayan Lee Thompsom Ávila \\ Anne Isabelle Vituri Berbert ${ }^{1}$
}

\begin{abstract}
RESUMO: Apresenta os resultados da Aula-Oficina (BARCA, 2004) realizada pelo PIBID História da Universidade Estadual de Londrina, nos Colégios Gabriel Martins e Tsuru Guido e, cuja temática é a utilização de HQs no ensino de conceitos históricos para alunos do $6^{\circ}$ ano. No ensino fundamental conceitos como "representação" e "fonte histórica", considerados como conceitos de segunda ordem (LEE, 2001), não são diretamente trabalhados com os alunos, apenas empregados para explicar conceitos substantivos (como "império", "revolução", "república"). Nossa proposta foi trabalhar alguns conceitos de segunda ordem diretamente, utilizando para isso as HQs de Abert Uderzo e René Goscinny "Asterix e Obelix" e partindo das pesquisas de LANGER (2006) e NOGUEIRA (2009) a respeito do uso de HQs no ensino de conceitos históricos. A discussão em torno deste tema feita pelos autores supracitados sugere que o uso de HQs mantém a atenção das crianças por mais tempo que outras mídias, sendo, a nosso ver, apropriado para o ensino de conceitos de segunda ordem e exemplificação sobre contextualização da produção deste material.
\end{abstract}

Palavras-Chave: Educação Histórica. Conceitos de segunda ordem. História em Quadrinhos. Docência. Aula-oficina.

ABSTRACT: Introduce the results of the Aula-Oficina (BARCA, 2004) done by History PIBID from Universidade Estadual de Londrina, at the schools Colégio Gabriel Martins and Tsuru Oguido, and whose thematic was the usage of comics in teaching historical concepts to 6th year students. In basic education, concepts like "representation" and "historical source", second degree concepts (LEE, 2001), are not directly taught to the students, these words are used only to explain substancial concepts (such as "empire", "revolution", "republic"). Our intent was to teach directly some second degree concepts, using the comics by Albert Uderzo and René Goscinny "Asterix and Obelix" for it, according to LANGER (2006) and NOGUEIRA (2009)'s research on using comics to teach historical concepts. The debate around this theme done by the authors named above suggests that the usage of comics keep the children's attention for more time than other kinds of media being, in our understanding, apropriate to teach second degree concepts, as well as it is usefull to exemplify how the context of production.

Keywords: Historical education. Second degree concepts. Comics. Teaching. Aula-Oficina.

1 Graduandos em História pela Universidade Estadual de Londrina. Bolsistas do PIBID/CAPES. 


\section{Introdução}

Este trabalho apresenta os resultados da Aula-Oficina (BARCA, 2004), cujas fontes históricas utilizadas foram os quadrinhos de Asterix e Obelix de René Goscinny e Alberto Uderzo, que seria uma ponte para o trabalho de conceitos históricos de segunda ordem (LEE, 2001) como "representação" e "fonte histórica", conceitos esse que não são trabalhados diretamente com os alunos. Quando são utilizados, esses conceitos históricos de segunda ordem (LEE, 2001) estão associados a explicação de conceitos substantivos como "império", "revolução", e "república", entretanto não são trabalhadas suas definições.

Nossa proposta foi trabalhar alguns conceitos de segunda ordem diretamente, no entendimento de que estes conceitos são fundamentais para a aprendizagem da história. Utilizamos para isto as histórias em quadrinhos, baseando-se nas ideias de LANGER (2006) e NOGUEIRA (2009) que entendem o uso das mesmas como uma ferramenta relevante no ensino de história, por manterem a atenção das crianças por mais tempo que outras mídias, (por exemplo, filmes). $E$, em nosso entendimento são apropriadas para o ensino de conceitos de segunda ordem, (LEE, 2001) bem como para exemplificar como o contexto de produção de uma obra influência a forma como os autores abordam o conteúdo exposto pela mesma.

\section{Contextualização Teórica}

\subsection{Definindo "Conceitos Históricos de Segunda Ordem"}

Peter Lee (2001) entende como conceitos de segunda ordem aqueles conceitos que estão ligados à natureza do conhecimento histórico, ou seja, remetem à construção da pesquisa histórica, conceitos como narrativa, relato, explicação, interpretação e compreensão são citadas por LEE (2001) como exemplos que se encaixam em sua definição de Conceitos de segunda ordem, e complementa argumentando: 
Existem conteúdos substantivos como agricultura, revolução, monarquia, que são muito importantes. Embora a compreensão dos conceitos substantivos seja muito importante, na Inglaterra começamos a ter em conta outros tipos de conceitos, também os conceitos de 'segunda ordem'. É este tipo de conceitos, como narrativa, relato, explicação, que dá consistência à disciplina. É importante investigar as idéias das crianças sobre estes conceitos, pois se tiverem idéias erradas acerca da natureza da História, elas manter-seão se nada se fizer para contrariá-las. (LEE, 2001, p.15)

OLIVEIRA e SCHMIDT (2011), a partir de LEE (2001), vão dizer que os alunos precisam compreender os motivos que levaram os indivíduos no passado a agirem como conta a história, e de que forma esta história foi contada e possivelmente o porquê, e que se torna mais interessante aos alunos, no sentido da aprendizagem em história, quando lhes é exigido que compreendam as particularidades a partir das evidências e de como as mesmas são utilizadas para construir narrativas e interpretações do passado.

Portanto, nosso objetivo ao trabalhar com o Conceito de segunda ordem de LEE (2001), foi alcançar aquilo que é argumentado por OLIVEIRA e SCHMIDT (2011), isto é, fazer que os alunos de nossa Aula-Oficina (BARCA, 2004), no sentido do aprendizado histórico, compreendessem as particularidades a partir das fontes utilizadas, no caso as HQs, e de como as mesmas são utilizadas para construir narrativas e interpretações do passado.

\subsection{As HQs como documento histórico em sala de aula}

O contexto de criação das primeiras histórias de Asterix e Obelix era uma Europa que já tinha superado as privações da Segunda Guerra Mundial e de seus anos posteriores, vivendo o assim chamado "Milagre Econômico". Nesse momento também, a Europa ocidental apresentava um processo de invasão cultural estadunidense. O cinema, a música e os quadrinhos provenientes dos Estados Unidos tomaram espaços e conquistaram o público. Como uma forma de crítica e sátira a essa invasão "imperialista", o 
roteirista René Goscinny e o desenhista Albert Uderzo criaram o herói Asterix (inspirando-se em Vercingétorix, um líder da resistência gaulesa ao Império Romano).

Embora Goscinny tenha afirmado que não houve a intenção de se estabelecer uma relação entre os invasores romanos do ano 50 a. C. e os norte-americanos da década de 1950, é difícil não pensarmos nesta identificação, reforçada pelas inúmeras referências ao mundo contemporâneo.

As histórias em quadrinhos, ou simplesmente HQs, são bastante populares na cultura ocidental devido a sua linguagem simples e ao seu grande apelo imagético, sendo que a grande maioria dos personagens dessas histórias acabou sendo explorado por outros meios de comunicação de massa, como o cinema ou a televisão, e alguns personagens, como Superman, Batman e o Spiderman, acabaram se tornando símbolos culturais no mundo ocidental.

As HQs são um produto cultural produzido pelos seres humanos e, portanto refletem o momento histórico em que estão inseridos, isto é, são indicadores das percepções, dos gostos e das representações de uma sociedade. (BONIFÁCIO; CERRI, 2006, p.6) Nesse sentido, André Luiz Siqueira argumenta que os quadrinhos possuem uma dimensão maior que aparentam ter:

As HQs não podem ser reduzidas apenas a um passatempo, uma vez que guardam 'codificadas', em seus jogos de palavras, em imagens, informações importantes não somente sobre a época em que estas foram criadas, mas sobre as ideologias e cosmovisões que expressam, seja com um rigor apologético ou mesmo com bom-humor refinado, seja implícita ou explicitamente. [...] $(2011$, p.2)

Portanto, a utilização das HQs em sala de aula, se justifica pelo fato delas constituírem um documento histórico que caracteriza uma época, e como essa temporalidade se apropriou e representou outra que está a quase dois mil anos de distância.

Por ser uma leitura rápida, fácil e bastante agradável aos alunos, seja em sua forma ocidental ou no estilo oriental, denominado mangá, é 
bastante difundida entre os estudantes do ensino básico, não há qualquer tipo de rejeição por parte dos estudantes na utilização das HQs em sala de aula , que, em geral as recebem de forma entusiasmada, sentindo-se com sua utilização, propensos a uma participação mais ativa nas atividades de aula (SILVA, 1985).

As histórias em quadrinho também permitem um dinamismo, muitas vezes ausente nas narrativas históricas tradicionais, além de possibilitar o trabalho com o cotidiano dos povos, suas diferenças culturais e as relações de poder. (VERGEIRO, 2007)

Flávio Calazans argumenta que quando as HQs são utilizadas como ferramenta de ensino, consegue-se prender a atenção do aluno mais do que outros recursos e ressalta que:

[...] os quadrinhos quando são projetados em sala de aula, como recurso para complementar 0 ensino de determinado conteúdo, prendem mais atenção dos alunos do que outros recursos, como o vídeo, por exemplo, porque permitem que ocorra uma leitura simultânea da página, podendo o leitor captar a ação em todos os seus tempos. (CALAZANS, 2004, p.17)

Isso é ressaltado por Natania A. Silva Nogueira, falando sobre as possibilidades da utilização das HQs em sala de aula, com o objeto de incentivo à leitura, e de compreensão de sua realidade.

As HQs podem ser utilizadas para estimular a leitura e o interesse dos estudantes pelas abstrações, mantendo 0 vínculo com o objeto formal e abrindo caminho para o desenvolvimento do raciocínio lógico e para a criação de instrumentos de compreensão da realidade social em que vivem. (NOGUEIRA, 2009, p.1)

NOGUEIRA ressalta também o papel que as histórias em quadrinho podem ter, como uma importante ferramenta de reflexão sobre o presente e o passado, deixando mais claros conceitos difíceis para os alunos como o de anacronismo ${ }^{2}$ por exemplo:

\footnotetext{
${ }^{2}$ Nós entendemos anacronismo como qualquer tentativa de se julgar eventos de outra época com os critérios e valores de nossa época.
} 
Este recurso pode auxiliar os estudantes a organizarem melhor suas ideias, a desenvolverem o raciocínio e fazer comparações entre passado e presente, compreendendo de forma mais clara conceitos como o de anacronismo, por exemplo. (NOGUEIRA, 2009, p.7).

Holien Gonçalves Bezerra (2003) fala que os quadrinhos facilitam o aprendizado da questão das temporalidades e diz:

Não se trata de insistir nas definições dos diversos significados de tempo, mas levar o aluno a perceber as diversas temporalidades no decorrer da História (...) Sendo um produto cultural forjado pelas necessidades concretas das sociedades, historicamente situadas, o tempo representa um conjunto complexo de vivências humanas. (BEZERRA, 2003, p.44)

\subsection{Anacronismos e representações nas histórias de Asterix e Obelix}

Quando há a utilização de Histórias em quadrinhos que abordam a temática histórica deve-se ter um cuidado, porque as representações feitas pelos autores podem incluir, por exemplo, preconceitos vigentes na época de produção da mesma e se não houver uma desconstrução desses preconceitos, eles vão acabar sendo reproduzidos.

Sobre isso Nogueira fala:

[...] história em quadrinhos é uma obra de ficção que retrata as ideias do autor e o contexto do período no qual foi produzida. Portanto, ela pode conter, por vezes, lacunas uma vez que não possuem compromisso explícito em retratar a realidade.[...] $\mathrm{O}$ fato de uma $\mathrm{HQ}$ ser ambientada em um tempo passado não sugere que seu conteúdo seja integralmente fiel ao contexto histórico. (NOGUEIRA, 2009, p.6)

Isso é exemplificado nas histórias utilizadas como fonte para as aulas desse artigo, é recorrente a utilização de personagens ditos históricos dentro do enredo de Asterix e Obelix que não pertenciam a Gália do período do Império Romano, como o caso de Napoleão Bonaparte e Mahatma Gandhi. 
Por outro lado Marcelo Fronza (2007) entende que dentro das histórias de Asterix e Obelix, esses anacronismos não devem ser considerados como erros históricos, pelo motivo de ser uma característica narrativa dessas histórias e diz:

Esses anacronismos e a descontextualização não devem necessariamente ser considerados como erros históricos, pois nas histórias em quadrinhos com temas históricos eles são elementos estruturais de sua narrativa. Inclusive pode ser que, para as histórias em quadrinhos, a noção de descontextualização não se aplique, pois a descontextualização do processo histórico tem como finalidade, neste artefato cultural, uma recontextualização estética da narrativa gráfica para que se gere estranhamento e humor no leitor. Talvez esta seja uma forma de permitir que o leitor construa o fenômeno da conclusão ou do preenchimento nas histórias em quadrinhos com temas históricos. (FRONZA, 2007, p.112)

Entretanto, o fato dos quadrinhos de Asterix e Obelix possuírem anacronismos não invalida a sua utilização como fonte em sala de aula, pelo contrário, sobre a utilização de quadrinhos com anacronismos, VERGUEIRO fala que é válido sua utilização pela possibilidade desses anacronismos serem utilizados como exemplos, aproximando esses alunos de um conceito que para eles é muito abstrato e diz:

Os quadrinhos que contém anacronismos também podem ser aproveitados no ensino de História, a começar pelo fato de, em si, servirem como exemplos que podem ajudar o estudante a compreender o conceito de anacronismo. Esse conceito pode parecer óbvio para os historiadores e professores de História, mas também por demais abstrato e de difícil compreensão para estudantes do ensino básico (VERGUEIRO, 2007, p.21)

Para exemplificar a questão dos anacronismos nas histórias de Asterix e Obelix, nós nos utilizamos nas Aulas-Oficinas (BARCA, 2004) de três passagens de Asterix e Cleópatra, na primeira observa-se um marinheiro do barco de Asterix que admirado por ter terminado a sua viagem de volta do Egito, avisa a todos no barco que tinha avistado terra, mas para ilustrar isso, os quadrinistas se utilizam de um mapa da França 
contemporânea, que se difere muito da Gália no período do Império Romano.

Em outro ponto, há um diálogo entre dois egípcios e Asterix em um banquete, em que os egípcios falam que vão construir pirâmides. Entretanto, isso é equivocado pelo fato que no período representado, os egípcios já não construíam pirâmides.

Além disso, há inúmeros estereótipos no enredo de Asterix e Obelix. Johnni Langer (2006), em sua análise sobre os filmes e as HQs de Asterix e Obelix ressalta dois estereótipos presentes dentro das HQs que são frutos de visões criadas no século XIX sobre os povos Vikings.

O primeiro é referente ao equipamento, o famoso capacete com chifres, uma imagem criada pela ilustração literária e depois popularizada pela ópera oitocentista. [...] [o Segundo] a visão que os quadrinistas criaram sobre a aldeia de Asterix provém também do Oitocentos e da glorificação nacionalista de um passado romântico, idealizado, glorioso e invencível (os gauleses nunca são derrotados por ninguém em toda a série). (LANGER, 2006, p.269)

Um ponto interessante trabalhado nessa mesma história de Asterix é a questão de como os autores da $\mathrm{HQ}$ fazem a apropriação de outras representações sobre o período do Império Romano.

Todavia, deve-se dizer qual é o conceito de representação utilizado por nós, apesar do conceito de representação ser tão amplo e tão difícil de ser delimitado, nós optamos pelo conceito de representação de Roger Chartier,o qual diz que pode se entender as representações como formas de apreender, pensar, classificar e construir uma realidade social individual e socialmente (CHARTIER, 1990). Ou seja, CHARTIER entende o ato de construção dessas representações como algo que acontece na mente do indivíduo, mas a partir da apreensão do uso de símbolos socialmente compartilhados e de comum compreensão, de modo que as representações se constroem através de práticas sociais e culturais, embora a apropriação destas representações pelos sujeitos não se dê de forma automática, mas sofra influência do contexto que os cercam e das histórias de vida de cada um. (ENTREVISTA, 1999) 
As HQs de Asterix e Obelix são uma valiosa fonte para se trabalhar assuntos como o Imperialismo dos séculos $\mathrm{XIX}$ e $\mathrm{XX}$, ou até inserir eles dentro do contexto atual, como as Revoltas da Primavera Árabe, isso também é dito por NOGUEIRA (2009):

(...) [As HQs] Representa uma excelente referência para se estudar questões referentes à sociedade europeia contemporânea, com destaque para o imperialismo norte-americano (representado por Roma) e suas consequências sobre a Europa e a França (representadas pela aldeia gaulesa que resiste à dominação). (NOGUEIRA, 2009, p.7)

Portanto, a utilização das HQs como fonte histórica em sala de aula se justifica pelo fato delas serem um documento que caracteriza uma época, e como uma temporalidade se apropriou e representou seu próprios problemas e questões.

Além disso, é uma importante ferramenta que auxilia na compreensão de conceitos difíceis como representações e anacronismos devido a sua característica de ser um recurso de leitura rápida e de fácil compreensão pelos alunos, sendo bastante útil para se entender uma temporalidade que pode ser abstrata e distante para os alunos de um sexto ou sétimo ano do ensino básico.

\section{Atividades práticas}

\subsection{Proposta prática}

Nós propusemos a elaborar aulas que permitissem ao aluno de $6^{\circ}$ ano uma compreensão de alguns conceitos históricos como "fonte histórica", "representação" (conceitos de segunda ordem) e ainda noções de "império" e "república" (conceitos substantivos), na medida em que notamos que o ensino tradicional ensina os acontecimentos históricos presumindo que os conceitos usados para tal são autoexplicativos.

Utilizamos para nossa pesquisa o paradigma educacional da aulaoficina (BARCA, 2004) que leva em conta o saber multifacetado, em seus vários níveis (senso comum, ciência, etc) e utiliza como instrumento de avaliação materiais produzidos pelos alunos. Fizemos o uso de histórias em 
quadrinhos como recurso didático (FRONZA, 2007) e aplicamos um questionário exploratório dos conhecimentos prévios dos alunos, de modo que nos servissem de base para que nossas atividades posteriores correspondessem ao nível de entendimento que os alunos já possuíam.

\subsection{Aplicação das atividades do piloto}

Nossa primeira intervenção em sala de aula ocorreu em Dezembro de 2011, com a aplicação do piloto do nosso projeto em alunos do $6^{\circ}$ ano no Colégio Estadual Gabriel Martins. Propusemos 3 atividades divididas em 3 aulas, que consistiam em perguntas que seriam respondidas após a discussão dos temas, e análise dos quadrinhos que também constavam nas folhas de atividade de cada aluno. Neste piloto, analisamos os conceitos de "império", "fonte histórica", "representação" e a noção de "anacronismo".

Ao tabularmos os resultados, notamos que a ideia de anacronismo, bem como outras noções temporais, ficou obscura para a grande maioria dos alunos. A referência dos alunos dividia majoritariamente "verdade" e "mentira", causado pela tomada literal e dicotômica da questão do autor dos quadrinhos inserirem elementos de seu tempo, no tempo dos personagens. Os alunos não compreenderam a relação de intencionalidade do autor, tendo apenas as categorias classificatórias de "verdade" e "mentira". Outra observação importante: é dito que os alunos prestam mais atenção em histórias em quadrinhos do que em qualquer outra mídia (LANGER, 2006; NOGUEIRA, 2009) porém, notamos que os alunos se dispersam mais facilmente quando o material de trabalho está em suas mãos, do que quando o material de análise está à frente da sala e a observação é coletiva. Entendemos, portanto, que as crianças de $6^{\circ}$ ano prestam mais atenção coletivamente, quando é proposto pelo professor, e localizado à frente de todos, do que quando Ihes é pedido que analisem o material em suas mãos.

Nesta turma, a noção de "fonte histórica" a priori, incluía vários tipos de documentos: escrito, roupas, objetos, e possuía a definição de "tudo que foi criado pelo homem". Apesar do espectro de objetos capazes de serem consideradas fontes históricas, a história em quadrinhos não era 
enquadrada nesta categoria, sob o argumento de que "era feita para divertir, não para ensinar, e por isso poderia ser mentirosa." Analisados estes resultados, fizemos algumas alterações que julgamos necessárias para a aplicação definitiva da aula-oficina. Reduzimos o número de questões escritas, introduzimos uma atividade final de produção de historia em quadrinhos pelos alunos, trouxemos a discussão, os conceitos, e imagens para o quadro e a TV-Pen Drive, de modo a captar a atenção coletiva para as imagens analisadas.

\subsection{Execução da Aula-Oficina}

A execução do nosso projeto de aula-oficina deu-se em abril de 2012, com uma turma de $6^{\circ}$ ano do Colégio Estadual Tsuru Oguido. Trabalhamos com os quadrinhos de Asterix e Obelix relativos à guerra contra os soldados romanos. Nossa primeira tarefa foi a aplicação do questionário de conhecimentos prévios, e obtivemos os seguintes dados:

1. Acerca da noção de "Império": mais da metade associou este conceito a um lugar; 50\% fizeram referências à figura do imperador, destes, a metade definiu império como o local onde o imperador mora, e a outra metade definiu como o lugar onde o imperador governa. As palavras "rei" e "reino" apareceram em $20 \%$ das respostas. Um aluno apenas descreveu o império como um conjunto de pessoas: "Grupo de pessoas comandadas por um rei (sic)"; e duas alunas encontraram a explicação do substantivo "império" no verbo "imperar" definido por elas como o ato de "mandar". A partir disso, podemos inferir que a noção de império era obscura para essa turma de alunos, que se confundia com as noções de "reino", e só via explicação para o conceito, utilizando a noção da "profissão" de imperador. Menos de um quarto das crianças fez referência às riquezas e a guerras/exércitos, o que comprova a falta de base para formar o conceito, posto que a essência de um império é a busca por aumentar o território e as riquezas. Esta palavra até então não era um conceito capaz de classificar outros casos que não o romano, que era o que estávamos tratando. 
2. Sobre quem foi e o que fez Júlio César: A imensa maioria sabia sua "profissão" de imperador - apesar de não saberem que obrigações e características isso implicaria; mais de $50 \%$ dos alunos se referiram a ele com os verbos no presente: "Ele é o imperador de Roma"; os demais utilizaram os verbos no passado, mas não colocaram nenhum marcador cronológico. O único marcador cronológico que foi referenciado, e apenas por uma aluna, foi "antigamente". As noções acerca da função de um imperador, e do tempo em que isso ocorreu são confusas para eles. Por falarem com os verbos no presente, dão a entender que Roma ainda existe como a Roma Antiga, não veem continuidade da Roma de Júlio César para a cidade atual. Uma aluna descreveu este imperador como: "Ele foi um grande homem na história", incerta sobre o que este homem havia feito, ela tinha certeza que seria algo grandioso, pois se não fosse, não estaria estudando sobre ele. Vemos aqui o ranço da história dos grandes homens, dos grandes acontecimentos, que está ainda vivo em muitas escolas.

3. O que é uma fonte histórica? Todos os alunos apresentaram uma gama variada de opções do que podemos considerar como fonte histórica: filmes, teatro, música, livros, histórias orais etc. Frisamos aqui, dois exemplos de respostas diferentes e representativas:

a) "Por exemplo: acontece uma catástrofe, e ela fica na mente das pessoas, ou seja, fonte (o que já foi, mas jamais se esquece)".

b) "Uma fonte histórica é onde estão os nomes de personagens, as ilustrações, os autores e narradores da história"

Na resposta $A$, vemos novamente a ideia de que a fonte histórica, ou a historia, retrata eventos grandes e inesquecíveis. Na resposta $B$, temos a noção da história como algo dado, esperando que os historiadores apenas descubram a fonte, que falará por si própria a verdade da época em que foi produzida.

4. Acerca da influência da opinião do autor na produção de fontes históricas: $65 \%$ das crianças acreditam que a opinião do autor pode influenciar na sua produção, e os demais disseram não saber se isso era 
possível. Uma aluna disse não acreditar em tudo que os autores escrevem, demonstrando mais uma vez a dicotomia mentira $x$ verdade que tinha sido expressa pelos alunos da turma onde realizamos o piloto do projeto. Um aluno deu a seguinte resposta:

a) "Sem a opinião dos povos antigos (idosos) não existiriam mitos, histórias etc. Meu vô dizia que tinha um bicho (caipora) que fazia trança no cabelo dos cavalos. O cavalo encostava na cerca e o bicho fez uma trança com o cabelo do rabo do cavalo e o arame da cerca (sic)". Este discurso demonstra a ideia do aluno de que as fontes históricas são produzidas pelos antigos, e que depende deles a passagem das historias antigas adiante. Também demonstra o senso de que as histórias populares, o folclore, também são objetos da História.

5. Análise de imagem: tínhamos uma pintura de Napoleão grande, forte, montado em seu cavalo branco, brandindo uma espada, e a imagem do mesmo imperador sentado, casmurro, acima do peso. Pedimos que analisassem a diferença entre as imagens, e que pensassem na intenção dos autores de cada imagem. Primeiramente, quase metade dos alunos se referiu às pinturas como "fotos", e por isso, reivindicaram veracidade das imagens. Mais da metade reparou na diferença guerra/paz de uma imagem para a outra; $40 \%$ dos alunos disseram que as imagens retratavam dois tempos distintos: Napoleão jovem, e Napoleão velho. Algumas respostas representativas:

a) "Representam a mesma pessoa, só que na imagem 2 ele está diferente. Podem imaginar ele gordo sentado em um banco, mas ele é o maior imperador francês."

b) "Na foto 1 ele é um guerreiro, na 2 ele está sentado como uma pessoa comum."

c) "Na 1 está no cavalo se preparando pra guerra e na 2 está sentado com uma cara murcha. É uma imagem do que está acontecendo."

$\mathrm{Na}$ análise $\mathrm{A}$, vemos a dicotomia "pensamento $\mathrm{x}$ realidade". Podem pensar que ele era de um jeito, mas na verdade não era. Na resposta $B$, 
além de conter a palavra "foto", podemos distinguir a noção de que Napoleão não era uma pessoa comum, ele era um guerreiro, uma grande figura da história, novamente a História dos grandes homens. O aluno que fez a resposta C deixa claro que a imagem retrata os acontecimentos. Nenhum aluno fez alusão à intencionalidade do autor, nem à construção de imagem de um governante.

Devidamente estudados estes resultados dos questionários de conhecimentos prévios, executamos com os alunos a discussão de suas respostas, e a análise de algumas "tirinhas" dos HQs de Asterix e Obelix. Em relação à primeira atividade escrita, notamos que a caracterização de gauleses e romanos foi feita pela aparência física representada (gordos, barbados, com ou sem armadura) nos quadrinhos, em detrimento do caráter demonstrado por cada povo através de suas ações, provenientes de análises literais dos quadrinhos.

Quando foram pedidos para analisar duas imagens da redenção de Vercingetórix - atividade que seguia o molde de análise das imagens de Napoleão do estudo exploratório de conhecimentos prévios, agora após a discussão em sala de aula - obtivemos dados diferentes dos primeiros: Todas as respostas priorizavam a diferença dos gauleses na figura 1 para os gauleses na figura 2 , bem como a diferença dos romanos na figura 1 para os romanos na figura 2 , não incorrendo na diferença simples de romanos/gauleses. O que nos parece um demonstrativo da maior compreensão da tarefa de analisar imagens diferentes acerca de um mesmo assunto. A diferença na intenção dos autores foi citada em $25 \%$ das respostas, mas outros $25 \%$ das respostas ainda se focavam em diferenciar a figura de paz, da figura de guerra, como fizeram na análise das imagens de Napoleão.

Questionamos também, se todos os autores contam um mesmo evento, da mesma forma. Todos os alunos concordaram que cada autor conta diferente a história, a diferença entre as respostas ficou nos motivos para isso. Alguns alunos disseram que cada autor pensa ou vê o mundo de forma distinta, este segmento totalizou $60 \%$ dos alunos. Os outros $40 \%$ 
acharam que a diferença estava no modo de contar, que é próprio de cada autor.

Mais da metade dos alunos afirmaram que os quadrinhos são fontes históricas, e a mesma quantidade de alunos disse que os quadrinhos retratam o tempo em que os personagens viviam, e não o tempo em que o autor vivia. Um aluno, inclusive respondeu que os quadrinhos não podiam ser fontes históricas por que não vinham dos povos antigos. Ao serem indagados sobre a confiabilidade dos vários tipos de fontes históricas, obtivemos a esmagadora maioria relatando a diferença verdade/mentira em relação aos autores, e verdadeiro/falso em relação às fontes. Achamos importante ressaltar duas respostas:

a. "O texto e o desenho pode mentir, o objeto não (sic)"

b. "Um texto é verdade dependendo de quem escreve, e um desenho é só um desenho".

Temos na resposta $A$, a crença de que os objetos arqueológicos, ou mesmo da cultura material mais recente, não mentem, falam por si só, e são mais confiáveis que os textos escritos está presente. Na resposta $B$, temos o argumento de autoridade, de que o texto é verdadeiro dependendo da procedência, da reputação, do estudo do autor, e que o desenho (no caso, histórias em quadrinhos) são "só" desenhos, lúdicos e nada mais.

Para finalizar nosso trabalho, propusemos aos alunos, que em duplas, fizessem uma história em quadrinhos, que ensinasse o que é uma fonte histórica. Por ser uma atividade mais livre, e eles terem tido a oportunidade de fazer em casa, metade dos trabalhos que recebemos não tinham relação com o assunto, ainda que retratassem momentos históricos, como a vida de indígenas, seres do folclore e etc. Relataremos aqui 4 trabalhos que consideramos mais condizentes com a proposta, e ainda assim, diferentes entre si:

a) Relata a história de um menino que fica sabendo a história de um menino que morreu empinando pipa, através da leitura de um livro/jornal e se comove. Percebemos a ideia de uma historia passada adiante pelo ato de contá-la, no caso de maneira escrita, e a possibilidade de identificação ou comoção com a pessoa de quem se 
conhece a história. Lembramos aqui, que a história contada através desse quadrinho, que o personagem do quadrinho lê, não é de um grande evento, e sim de um evento simples com uma pessoa comum.

b) É a história de uma mãe contando para a filha o que é uma fonte histórica, e o faz através de um exemplo: "aconteceu uma guerra, essa guerra ficou marcada como uma fonte histórica, assim nos anos seguintes todo mundo sabia da guerra". Este grupo representou a fonte histórica como a ferramenta de perpetração da história de um grande evento.

c) Conta a história de dois cachorros falantes que se encontram no parque, e ao cavar a terra, acidentalmente encontram um documento (representado com um selo de cera vermelho no final, mostrando sua oficialidade e autenticidade) e o levam a um museu para exposição. Vemos representado aqui à ideia de que as fontes históricas são documentos oficiais, escritos e que pertencem a um museu para exposição, ideias da historia tradicional.

d) Representa dois amigos conversando sobre o porquê devemos valorizar os historiadores, os argumentos são: ele descobre o passado, e ele escreve algumas partes do livro da escola. Fica claro que o passado está enterrado - como na narrativa $\mathrm{C}$ - e cabe ao historiador apenas a tarefa de descobrir, de tirar do desconhecimento um documento, uma fonte, que representaria a historia tal como aconteceu.

\section{Considerações Finais}

Apesar de não ter sido unânime, percebemos que esta turma compreendeu melhor os conceitos de "fonte histórica", de "representação" e de "império" que a turma na qual realizamos o nosso piloto. Acreditamos que isso se deva a nossa mudança de táticas didáticas, como a redução do número de questões escritas, priorizando a interação que caracteriza a 
aula-oficina (BARCA,2004), e a chamada de atenção coletiva para frente da sala ao analisar imagens e mapas. Também percebemos que as HQs são úteis para a discussão de questões como as representações, a intencionalidade do autor, e problematizar a questão de fontes históricas.

Em relação à sua utilização para demonstrar a influência do tempo do autor na produção do quadrinho, o anacronismo, os quadrinhos não se mostraram muito eficazes, à medida que também são relacionados como "mentirosos para serem engraçados".

Compreendemos que os alunos do $6^{\circ}$ ano tendem a fazer análises literais de imagens, e ainda têm noções fortes da historia tradicional, e que saber disso é uma valiosa informação para que possamos preparar as aulas adequadamente de modo à descontruir este tipo de pensamento, e favorecer a construção de uma análise crítica que possa abstrair do literal e pairar sobre o campo das representações e intenções do autor.

\section{Referências}

BARCA, I. Aula Oficina: do Projeto à Avaliação. In. BARCA, I. Para uma educação de qualidade: Atas da Quarta Jornada de Educação Histórica. Braga, Centro de Investigação em Educação (CIED)/ Instituto de Educação e Psicologia,Universidade do Minho, 2004, p. 131-144.

BONIFÁCIO, S. de F.; CERRI, L. F. O ensino da história e as histórias em quadrinhos: algumas considerações. Disponível em < (Acesso em 30 mar.2012).

http://www.pucpr.br/eventos/educere/educere2006/anaisEvento/docs/CI090-TC.pdf>

CALAZANS, F. M. de A. História em quadrinhos na escola São Paulo: Paulus, 2004.

CHARTIER, R. A História Cultural: entre práticas e representações. Lisboa: Difel, 1990.

ENTREVISTA com Roger Chartier. Pós-História. Assis, v. 7, p. 11-13, 1999.

FRONZA, M. O significado das histórias em quadrinhos na educação histórica dos jovens que estudam no Ensino Médio, Curitiba, 2007.

Disponível em < http://www.lapeduh.ufpr.br/arquivos/2010-02-28-10-2625-dissertacao2007fronza.pdf> (Acesso em 8 abr.2012)

KARNAL, L. História na sala de aula: Conceitos, práticas e propostas. São Paulo, Contexto, 2003. 
LANGER, J. A volta dos bárbaros: Asterix e os vikings no cinema e na $H Q$ Revista História, imagem e narrativas n. 3, ano 2, setembro/2006 disponível em <http://www.historiaimagem.com.br/edicao3setembro2006/resenhaasterix.pdf> (Acesso em 15 fev.2012).

LEE, P. Progressão da compreensão dos alunos em História. In: BARCA, Isabel (Org.). Perspectivas em Educação Histórica: Actas das Primeiras Jornadas Internacionais de Educação Histórica. Braga: UMINHO, 2001, p. 15.

NOGUEIRA, N. A. S. Aprendendo história através das HQs: experiências e considerações. Disponível em <

http://pt.scribd.com/doc/12794646/Aprendendo-Historia-atraves-das-HQs $>$ Publicado em 25 fev. 2009. (Acesso em 15 fev.2012).

OLIVEIRA, T. A. D. de; SCHMIDT, M. A. M. dos S. Perspectivas de aprendizagem histórica: um estudo a partir de professores e sua relação com conceitos históricos de manuais didáticos Anais Eletrônicos do IX Encontro Nacional dos Pesquisadores do Ensino de História disponível em < http://abeh.org/trabalhos/GT07/tcompletothiago.pdf> (Acesso em 08 jun. 2012)

RAVIL, L. História e Paródia em Asterix, 2012. Disponível em http://seguindopassoshistoria.blogspot.com.br/2011/01/historia-e-parodiaem-asterix.html (Acesso em 11 mai. de 2012)

SIQUEIRA, A. L. O ensino de conceitos históricos a partir dos HQs de "Hagar, o Horrível". Revista Eletrónica do Laboratório de Ensino e Pesquisa do Curso de História, Curitiba-PR, Jan. 2011. Disponível em < http://www.utp.br/lep/N2/artigos/o ensino.pdf> (Acesso em 30 mar. 2012). 


\section{ANEXOS}

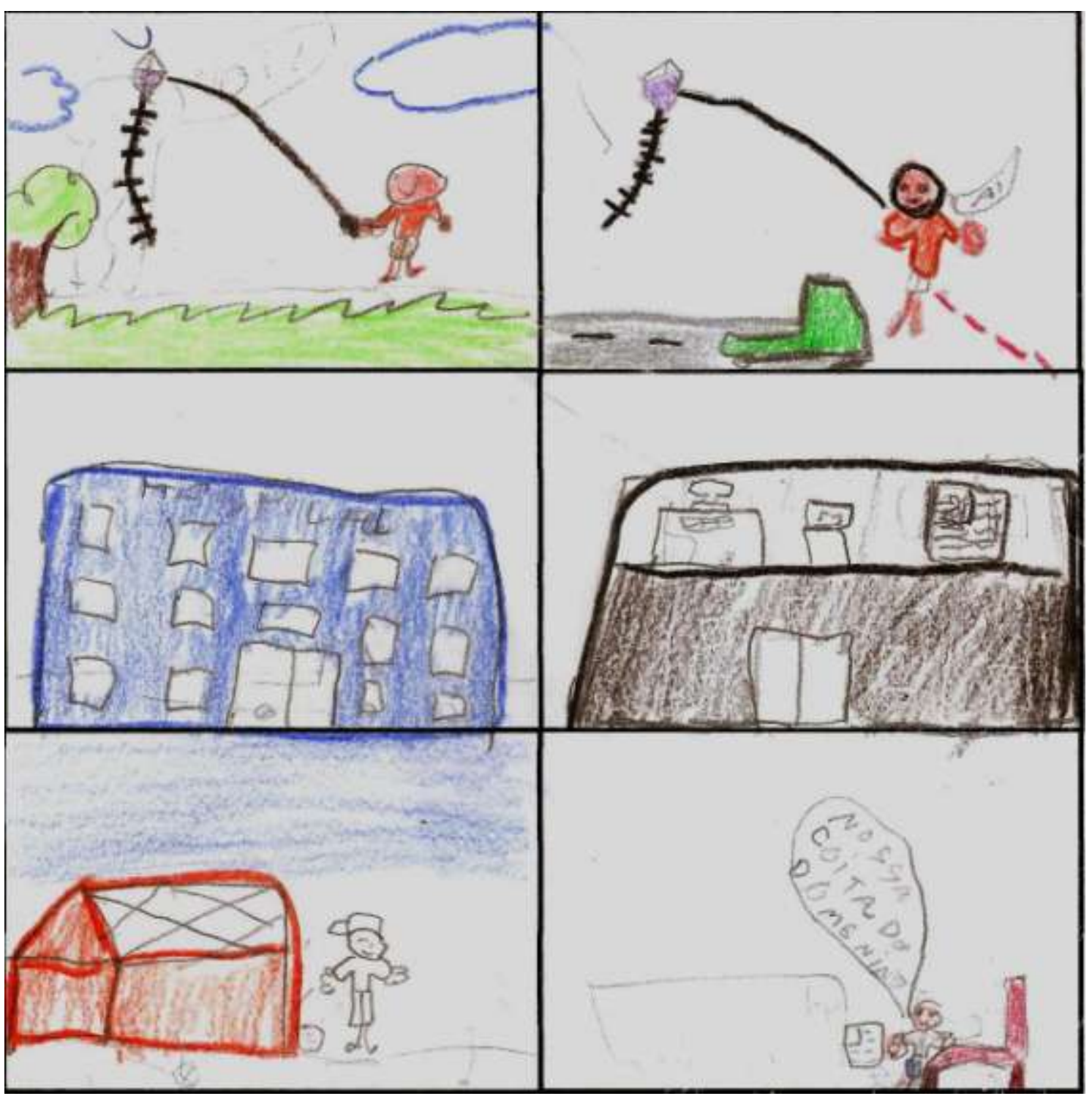

IMAGEM 1- Quadrinho produzido pelos alunos do $6^{\circ}$ ano, do Colégio Estadual Tsuru Oguido 


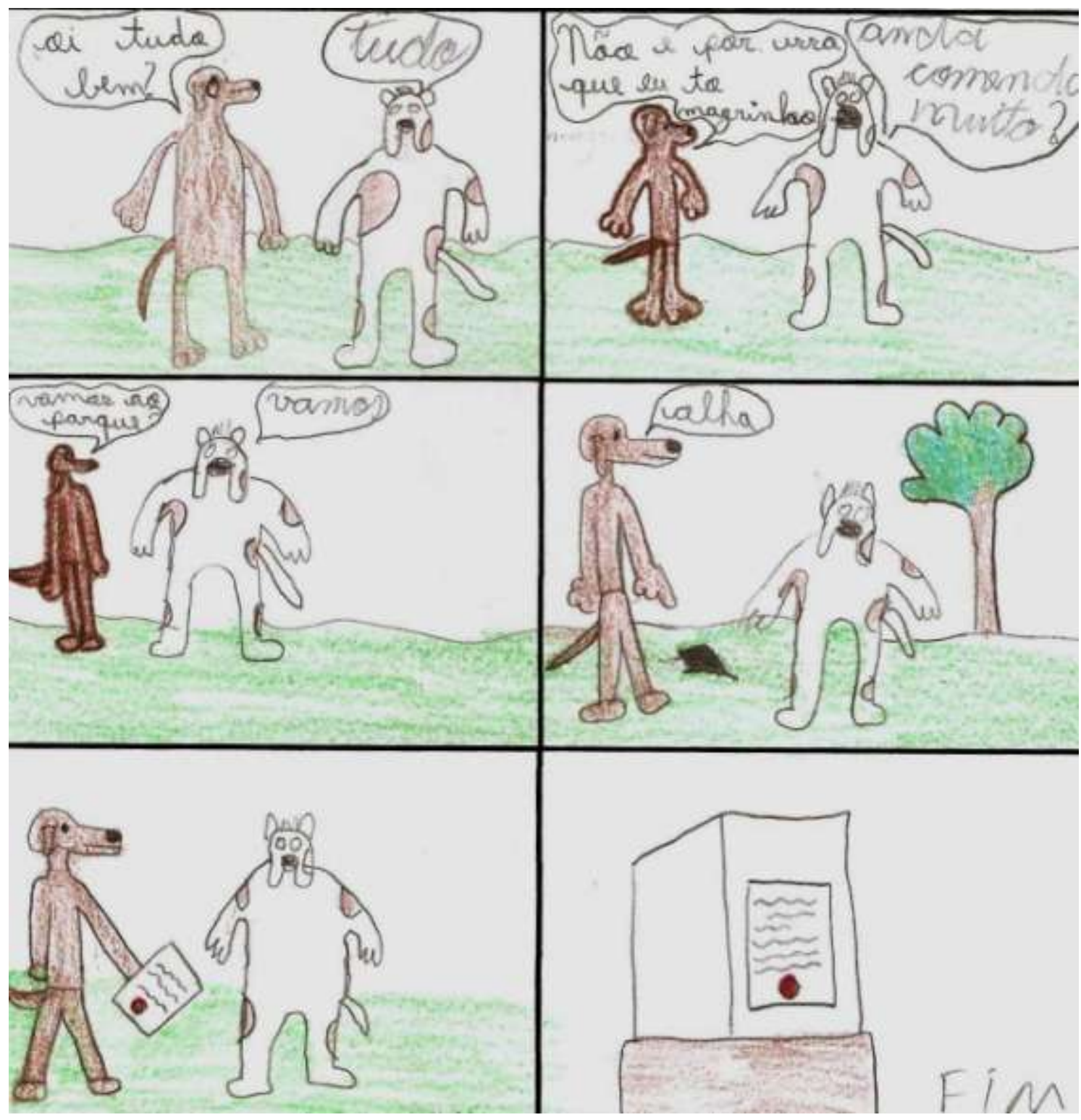

IMAGEM 2- Quadrinho produzido pelos alunos do $6^{\circ}$ ano, do Colégio Estadual Tsuru Oguido 


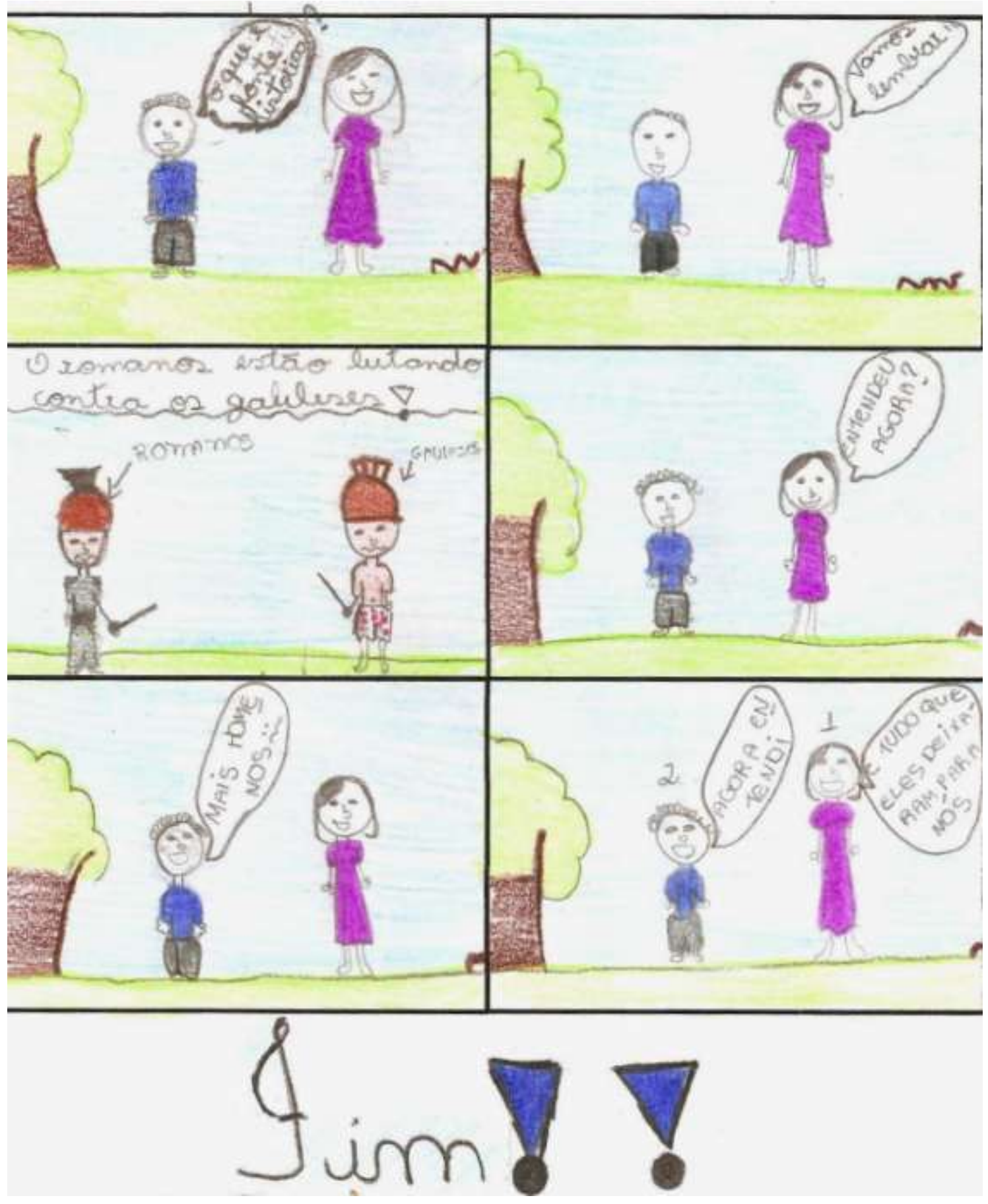

IMAGEM 3 - Quadrinho produzido pelos alunos do $6^{\circ}$ ano, do Colégio Estadual Tsuru Oguido 


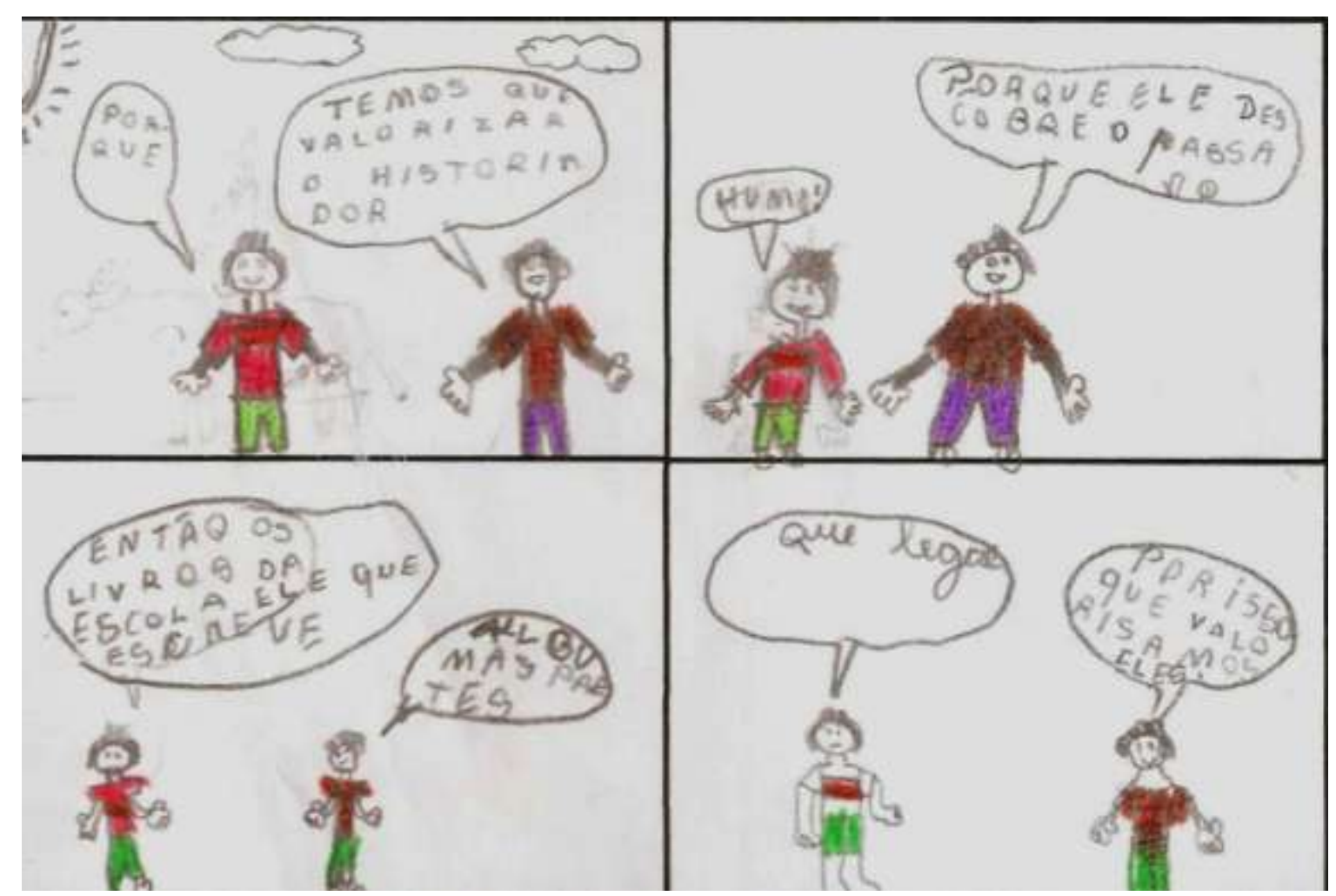

IMAGEM 4 - Quadrinho produzido pelos alunos do $6^{\circ}$ ano, do Colégio Estadual Tsuru Oguido 


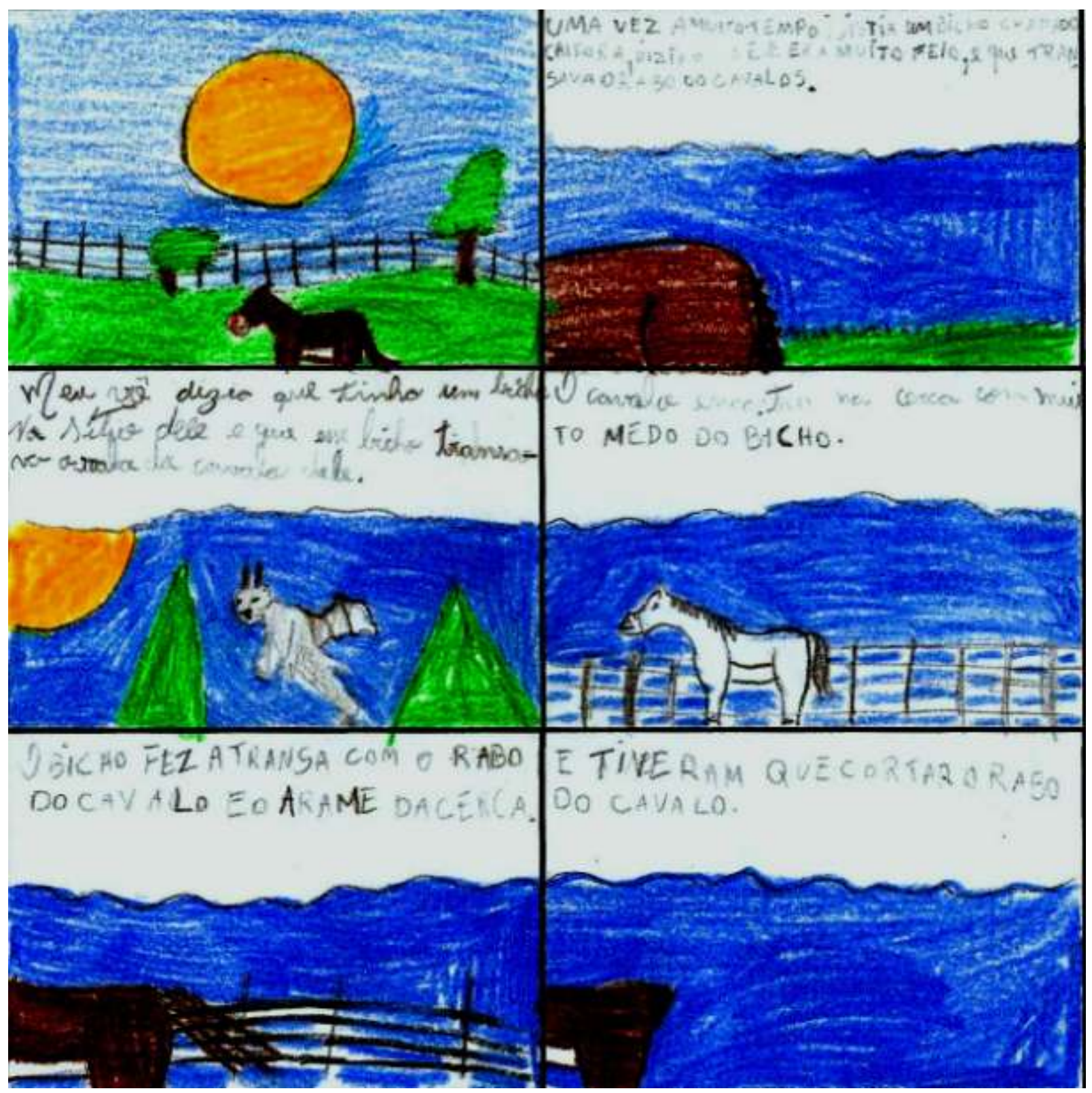

IMAGEM 5 - Quadrinho produzido pelos alunos do $6^{\circ}$ ano, do Colégio Estadual Tsuru Oguido, retratando uma história do folclore, contada por seu avô. 


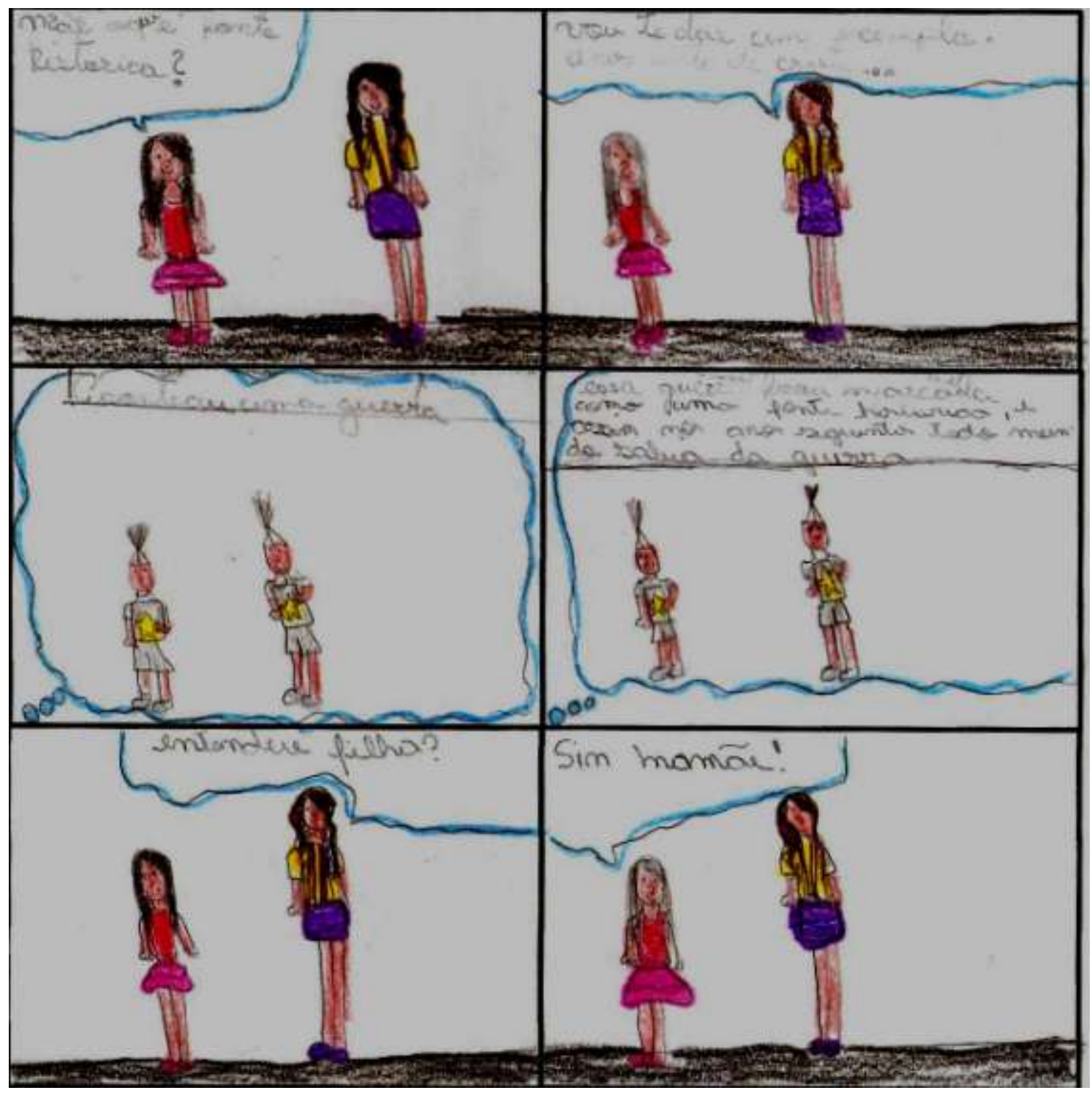

IMAGEM 6 - Quadrinho produzido pelos alunos do $6^{\circ}$ ano, do Colégio Estadual Tsuru Oguido 